\title{
A autorrepresentação do judeu mediada pelo olhar do nacional em "Natal sem Cristo" de Samuel Rawet
} Saul Kirschbaum ${ }^{1}$

Tente um dia ser mulher, judia e feia. Você vai acabar implorando para ser preto. Desculpe a nossa falha: pardo.

Salman Rushdie

Julgar a situação social com base apenas na posição econômica ou política é arriscado. A aceitação da etnicidade hifenizada por parte do grande público, no Brasil, permanece contestada, e os termos "árabe", "turco" e "japonês" continuam a ser aplicados a pessoas de ascendência não-européia, quer sejam eles ministros importantes ou proprietários da livraria do bairro.

Jeffrey Lesser

Samuel Rawet nasceu em um shtetl ${ }^{2}$ na Polônia em 1929 e emigrou para o Brasil, com sua família, em 1936. Importa lembrar que a Polônia, desmembrada no final do século XVIII entre Rússia, Prússia e Áustria, somente voltou à condição de Estado independente no final de 1918, após a Primeira Guerra Mundial. Sua consolidação se deu em 1919, ao abrigo do Tratado de Versalhes, o que resultou no estabelecimento de uma situação que Ettinger explica nos seguintes termos:

A conquista de independência política trouxe consigo uma irrupção de sentimentos nacionais entre as populações majoritárias dos novos Estados. O júbilo com a recém-obtida independência, o desejo de acertar contas com velhos "inimigos" e a falta de confiança na estabilidade das novas instituições levaram líderes dos partidos nacionalistas e o público em geral naqueles Estados a adotar uma atitude hostil em relação às minorias, para tentar reduzir sua influência e seu valor tanto quanto possível, forçando-as a se assimilarem ou a emigrarem (Ettinger, 1976, p. 953-954, tradução nossa).

\footnotetext{
${ }^{1}$ Doutor em língua hebraica, literatura e cultura judaica pela Universidade de São Paulo (USP), São Paulo, SP, Brasil. E-mail: saul.kirschbaum@gmail.com

${ }^{2}$ Do ídiche: "cidadezinha”, "vila", "aldeia”.
} 
Em consequência, logo a seguir, a situação dos judeus poloneses tornou-se insustentável, com sua exclusão de muitas atividades econômicas, profissões liberais e administração pública, pesada tributação e até mesmo a ocorrência de pogroms, ${ }^{3}$ provocando um forte êxodo que, em boa parte, dirigiu-se para o Brasil. ${ }^{4}$ Muitas vezes, como aconteceu com os Rawet, o chefe da família emigrava antes, sozinho, na expectativa de acumular recursos que possibilitassem a saída, mais tarde, da esposa e dos filhos.

Apesar de ter vindo para cá com apenas 7 anos, Rawet nunca chegou a se integrar completamente, a superar sua autopercepção de imigrante, de diferente. Esse estranhamento se tornou manifesto em entrevistas, em ensaios e em obras de ficção de sua autoria. Em 1972, por exemplo, em depoimento a Flávio Moreira da Costa publicado no jornal carioca Correio da Manhã, Rawet diria: "Eu aprendi o português nas ruas, apanhando e falando errado, e acho essa a melhor pedagogia" (Costa, 1972). ${ }^{5}$

Para falarmos como Julia Kristeva, do ponto de vista jurídico, "o estrangeiro é aquele que não pertence à nação em que estamos, aquele que não tem a mesma nacionalidade" (Kristeva, 1994, p. 101) - condição que, em tese, pode ser revertida pela adoção da nacionalidade do Estado receptor. E é fato que, no plano das mentalidades, com implicações diretas nos relacionamentos sociais, para continuarmos citando a pensadora búlgara,

o estrangeiro é aquele que não faz parte do grupo, aquele que não "é dele", o outro. [...] Se voltarmos no tempo e nas estruturas sociais, o estrangeiro é o outro da família, do clã, da tribo. Inicialmente, ele se confunde com o inimigo. Exterior à minha

\footnotetext{
${ }^{3}$ Do russo, "causar estragos", “destruir violentamente". Ver, por exemplo, Ettinger (1976, p. 953955), em especial: "O nascimento da independência polonesa também foi acompanhado por tumultos antijudaicos. Membros das legiões que lutaram pela liberação da Polônia, incluindo poloneses dos Estados Unidos, invadiram lares judaicos, assassinaram e pilharam, estupraram mulheres, rasparam as barbas e cachos laterais dos homens e praticaram todos os tipos de perseguição" (1976, p. 954, tradução nossa).

${ }^{4}$ Ettinger informa que, apesar das severas restrições à imigração impostas pelos Estados Unidos, mais de 600 mil judeus saíram da Europa entre 1926 e 1938 (Ettinger, 1976, p. 947), e Jeffrey Lesser mostra que 14.609 judeus imigraram da Polônia para o Brasil entre 1925 e 1935 (Lesser, 1995 , p. 318). Alguns judeus que não lograram ser aceitos nos Estados Unidos mudaram seu destino para o Brasil.

${ }^{5}$ Essa entrevista foi posteriormente republicada por Flávio Moreira da Costa, com pequenas variações, na revista Escrita (ano I, n. 2, 1975), e no livro Vida de Artista: um livro de encontros e entrevistas (Porto Alegre: Editora Sulina, 1990).
} 
religião também, ele pode ser o infiel, o herético. Não tendo prestado fidelidade ao meu senhor, ele é nativo de uma outra terra, estranho ao reino e ao império (Kristeva, 1994, p. 100).

É na ficção de Rawet que a elaboração da diferença - da separação radical entre o nacional e o imigrante, entre o hegemônico e o minoritário - e do sentimento de exclusão manifestam-se com maior intensidade.

No conto "Gringuinho" (2004a), por exemplo, publicado em 1956 na coletânea Contos do imigrante, ${ }^{6}$ o protagonista - que não podemos deixar de ver como uma espécie de alter ego do autor -, menino recémimigrado, sente-se hostilizado pelos colegas de escola por sua dificuldade com a língua. A tal ponto que, em uma ocasião, reage pelas chamadas "vias de fato" ao coro das crianças que gritam "fala gringuinho", e acaba por bater na professora e retirar-se da sala de aula por decisão própria. Assim, a caminho de casa, sente-se excluído da escola, para onde acha que não mais poderá voltar.

Essa temática é também retomada em vários outros $\operatorname{contos}^{7}$ bem como nas novelas Abama, de 1964, e Viagens de Ahasverus..., de 1970.

O que acontece quando um judeu se vê participando de uma das mais importantes festividades cristãs, um evento que pressupõe cordialidade, convívio amigável e fraternal entre todos os presentes? É o que ocorre no conto que iremos analisar, "Natal sem Cristo", publicado em 1963 na coletânea Diálogo, e republicado em 2004 em Contos e novelas reunidos.

Nehemias Goldenberg, judeu, 30 anos, professor de História, é convidado por seu amigo Sílvio, professor no mesmo ginásio, para a ceia de Natal de sua família. Assim, o judeu Nehemias e os 11 cristãos que compõem o grupo familiar de Sílvio estão sentados ao redor da mesa do jantar para uma alegre celebração. ${ }^{8}$ Não obstante, Nehemias logo se percebe como o intruso (Rawet, 2004b, p. 124), a nota destoante daquele que devia ser um encontro harmonioso; como se tivesse "o

\footnotetext{
${ }^{6}$ Esse conto foi incluído na coletânea Os cem melhores contos brasileiros do século, organizada por Ítalo Moriconi e publicada em 2000 pela editora Objetiva.

${ }^{7}$ Ver, por exemplo, "A prece", na coleção Contos do imigrante, "Reinvenção de Lázaro", em $O$ terreno de uma polegada quadrada, e "O casamento de Bluma Schwartz", em Que os mortos enterrem seus mortos.

${ }^{8}$ Note-se que o número total de participantes é o mesmo que o número de apóstolos que participaram da Última Ceia. Aqui, o próprio Jesus está presente na forma de um Cristo barroco crucificado, atrás da matriarca Nani. Nehemias estaria incorporando o papel de Judas Iscariotes, o estereótipo do judeu traidor no imaginário cristão?
} 
corpo exposto pelo avesso", "uma cauda de símio no cóccix", o "casco caprino" fendido a "golpe[s] de risos" (Rawet, 2004b, p. 123); Rawet parece estar parafraseando Homi Bhabha, é como se "os olhos do cristão destroça[sse]m o corpo do judeu" ${ }^{9}$

O nome do protagonista não é nada fortuito. Nehemias é a figura central do livro bíblico de mesmo nome, governador da Judeia sob Artaxerxes I da Pérsia, que teve um papel proeminente na reconstrução de Jerusalém na época do Segundo Templo. Sua história é narrada, predominantemente, na forma de memória em primeira pessoa. Por sua vez, o sobrenome Goldenberg - "montanha dourada" em ídiche também dá à personagem uma posição de destaque e não deixa dúvidas sobre sua judeidade.

Vale a pena levar essa digressão mais longe. A Bíblia conta que, uma vez assegurada a defesa de Jerusalém pela edificação de seus muros e portas, Nehemias empreendeu um grande esforço de "purificação", de remoção de toda "contaminação": todos os retornados da Babilônia tiveram que "mostrar a casa de seus pais e a sua linhagem, se eram de Israel" (Ne, 7:61). Os sacerdotes cujos registros não foram encontrados, "como imundos, foram excluídos do sacerdócio" (Ne, 7:64). A seguir, valendo-se de sua autoridade de "tirsata" (governador), Nehemias impôs a todo o povo um novo pacto, um juramento de que "andariam na lei de Deus, que foi dada pelo ministério de Moisés, servo de Deus, e de que guardariam e cumpririam todos os mandamentos do Senhor, nosso Senhor, e os seus juízos e os seus estatutos" (Ne, 10:29). Entre outras prescrições, esse pacto determinava a exclusividade dos casamentos endogâmicos: "E que não daríamos as nossas filhas aos povos da terra, nem tomaríamos as filhas deles para os nossos filhos" (Ne, 10:30). Por fim, restabeleceu a estrita observância do shabat, postando guardas nas portas de Jerusalém, para impedir a entrada de comerciantes (Ne, 10:31, 13:15-22).

A própria presença de Nehemias na ceia faz com que se fale de judeus, e ele, ouvindo em silêncio o que cada um tem a dizer, chega bruscamente à conclusão de que "estava ali o universo, os outros e ele, com os mesmos lugares-comuns, e a mesma contradição insolúvel" (Rawet, 2004b, p. 124). Ou seja, o grupo ali reunido é representativo da sociedade mais ampla. Note-se que sua atividade profissional, professor

\footnotetext{
${ }^{9}$ Ver Homi K. Bhabha (1988, p. 73): "Os olhos do homem branco destroçam o corpo do homem negro e nesse ato de violência epistemológica seu próprio quadro de referência é transgredido, seu campo de visão perturbado".
} 
de história, indicia conhecimento e compreensão do relacionamento histórico das minorias judaicas com sociedades cristãs hospedeiras. ${ }^{10}$

Existe abundante literatura de ficção sobre a forma como as populações hegemônicas representam as minorias imigrantes. Para citar alguns poucos exemplos brasileiros, esse topos é relevante em obras como O tempo e o vento, de Érico Veríssimo (1955); Um rio imita o Reno, de Vianna Moog (1966); Cosmópolis, de Guilherme de Almeida (1962); ou mesmo O Estrangeiro, de Plínio Salgado (1948). Em "Natal sem Cristo", no entanto, através de reflexões sobre comentários de membros de uma mesma família, Rawet faz o percurso oposto e oferece um amplo panorama sobre como o judeu se vê representado pelos nacionais brasileiros, na época majoritariamente católicos.

A técnica narrativa empregada por Rawet nesse conto consiste, por um lado, em utilizar um narrador onisciente seletivo, em terceira pessoa, que, em discurso indireto livre, expressa as considerações de Nehemias a respeito do evento que está vivenciando. Por outro lado, apresenta, em discurso direto, a opinião de cada um dos cristãos presentes sobre os judeus, seguida imediatamente em fluxo de consciência, pela reflexão de Nehemias sobre o que acabou de ser dito. Esses procedimentos levam o leitor a adotar o ponto de vista de Nehemias, estabelecendo com ele uma proximidade, uma espécie de cumplicidade.

O "desfile" de opiniões é aberto pela observação de Luis, político profissional, irmão de seu amigo Sílvio, para quem "- São muito simpáticos os judeus, muito simpáticos. E um senso político extraordinário. Marx e Rotschild, Disraeli e Bernard Baruch... Senso político extraordinário. Têm o mundo nas mãos". Nehemias desconstrói a hipocrisia que se oculta sob a mítica inexistência de racismo no Brasil; para ele, a atitude condescendente de Luis, "o cerimonioso do tom, a frase claramente articulada, o empolamento dos nomes arrevezados" encobrem "o afago com o sabor de irônica palmada, mas que em hora de definições, ou de posição em perigo, tombará como rija paulada" (Rawet, 2004b, p. 126).

Para Albino, genro da matriarca Nani, os judeus são "grandes financistas, empreendedores". E Nehemias decodifica o conteúdo oculto dessa fala como conotando, na verdade, "trapaceiros", e pergunta-se se Albino teria em alguma ocasião se associado a judeus para cometer

\footnotetext{
${ }^{10}$ Paradoxalmente, essa mesma atividade profissional, professor de história, que o torna sensível às questões de estranhamento, o coloca no próprio centro de geração e reprodução de uma narrativa hegemônica, homogeneizadora da nação.
} 
trapaças, com resultados lucrativos, ou mesmo se alguma vez já conseguira ludibriá-los. Projeta que aquele, se por acaso vier a ser prejudicado nesse jogo - em benefício de judeus, afinal "alguém sempre se beneficia" -, mudará seu discurso para "a expressão mais rude, a invectiva sem aparas, decisiva, com o implícito do julgamento definitivo, sem apelação" (Rawet, 2004b, p. 126).

A respeito da representação dos judeus como financistas e empreendedores pela intelectualidade brasileira, vale a pena lembrarmos a crônica publicada por Humberto de Campos, membro da Academia Brasileira de Letras, à época da ascensão do nazismo, com o título de "Em favor de Israel". Nela, Campos manifesta sua indignação face à tragédia que, já em 1933, pairava sobre os judeus na Alemanha: "[o] mundo inteiro levanta-se, neste momento, em favor de Israel, ameaçado na Alemanha pelo antissemitismo de Hitler" (Campos, 1954, p. 245). Entre seus argumentos em defesa dos judeus, no entanto, encontramos a seguinte preciosidade:

Ele não oferece o seu dinheiro ao cristão. O cristão é que lho pede por empréstimo, submetendo-se aos juros que Israel estabelece, mas não impõe. Com esses juros, Israel prospera, enriquece, domina secretamente o mundo. $\mathrm{O}$ judeu jamais penetrou nos palácios da Espanha ou de Portugal pedindo aos príncipes e fidalgos do séquito real que ficassem com os seus sequins: príncipes e fidalgos é que o mandavam chamar e com ele negociavam. E quando se viram insolváveis, atribuíram-lhe toda a sorte de feitiçarias e calamidades (Campos, 1954, p. 248).

Humberto de Campos, "com muita empatia e solidariedade" apesar da menção expressa ao "domínio secreto do mundo"11 -, propõe por fim que "[o] Brasil devia, pois, abrir os braços a Israel, na hora em que o perseguem no Velho Mundo", mas com a ressalva: "Venham com os livros e com os livros de cheque. E só encontrarão irmãos, - desde,

\footnotetext{
${ }^{11}$ Cabe mencionar que do repertório antissemita, a partir da segunda metade do século XIX, fazem parte as acusações contra os judeus de "conspirar para estabelecer o domínio do mundo" (Protocolos dos Sábios de Sion), exercer controle sobre a imprensa e sobre as finanças mundiais ( $O$ judeu internacional, de Henry Ford), e, ao mesmo tempo, promover a revolução comunista internacional (Minha luta). A ideia de "domínio do mundo" já está contida no "têm o mundo nas mãos" da fala da personagem Luis.
} 
está bem visto, que não venham aumentar o número dos vendedores de móveis a prestações" (Campos, 1933, p. 18-19). ${ }^{12}$

Outra posição é a de Enéas, advogado, filho de Nani; “- E que argúcia! Admiráveis!”, diz ele. Para Nehemias, Enéas está enfatizando a argúcia dos judeus à luz daquela que ele próprio busca praticar, a argúcia

que empregas diariamente, numa eterna subversão de fatos, ideias, conceitos, provas, a que consegue sob o impacto de uma oratória bem planejada ofuscar a verdade de um deslize, [...] que, em nome de uma ética e de uma lógica, representa a negação destas mesmas (Rawet, 2004b, p. 126).

Até aqui, os comentários, se incorporam valores negativos, o fazem de forma velada, até mesmo, talvez, com a aparência de afirmar valores positivos - que, exatamente por isso, devem ser desconstruídos. Nas condições brasileiras, comentários socialmente aceitáveis.

Mas, na posição mais extrema do arco, Lenita, 17 anos, filha de Albino, pergunta: "- Mas não foram os judeus que mataram Cristo, papai?". Verbaliza assim, de forma clara e expressa, o desagrado que lhe causa a simples presença de Nehemias, sua reação de antipatia que já vem de encontros anteriores, submetendo o grupo a constrangimento que provoca ligeiro hiato, um impasse, a expectativa de "um aparte, de um movimento que sirva de pretexto para escamotear a resposta". Em Nehemias, a manifestação de Lenita evoca

a suma de milênios, a cristalização grosseira mas eficaz de tantas escolásticas, [...] reminiscências atávicas de tremores ante a procissão da Semana Santa de além-mar. O dia condensado em ódio, a ideia feita verbo, sim, e ação. Alquimia brutal a objetivar o resgate de carne, a despertar as garras que todos nós já tivemos algum dia (Rawet, 2004b, p. 126-127).

Desemboca, naturalmente, em derramamento de sangue. "Ali findam as querelas teológicas, ali se resume o corolário de montes de proposições deontológicas, ali se fecha o sorites gigantesco: sangue" (Rawet, 2004b, p. 127).

\footnotetext{
${ }^{12}$ A ambivalência não para por aí. Esta ressalva consta do texto original, compilado por Márcio Campos Lima em 1933, no livro Os judeus na Allemanha no momento actual, mas na republicação da crônica em 1954, em coletânea dedicada aos "párias", o trecho final foi substituído por "Venham com os livros de Moisés e com os livros de cheques. E só encontrarão irmãos, - e colocação do seu dinheiro a 12\%” (Campos, 1954, p. 250). Mascate será menos pejorativo do que agiota?
} 
Como se sabe, uma das vertentes do antissemitismo brasileiro é a herança colonial portuguesa, apoiada e alimentada pela instituição da Inquisição, aqui evocada pela referência à "procissão da Semana Santa de além-mar" e suas conotações de autos de fé e fogueiras. ${ }^{13}$

Outra vertente desse fenômeno, menos analisada, é o temor da concorrência judaica, que transparece nas falas de Albino e Enéas.

Na verdade, deve-se sempre suspeitar que a questão da proteção de posições já ocupadas, sejam elas postos de trabalho, cargos públicos ou atividades empresariais, contra a ameaça de novos concorrentes, esteja presente na hostilidade com que as populações hegemônicas ou as classes dominantes tentam manter grupos minoritários à distância. Fator correlato, que agrava esse quadro, é a importação de trabalhadores estrangeiros com o objetivo de manter os salários baixos e os trabalhadores nacionais sob pressão, submissos.

Malu, esposa de Enéas, tentando romper o silêncio embaraçoso criado pela pergunta de Lenita, "sorrindo com a indulgência de quem socorre o necessitado", acaba por manifestar a existência de preconceito em relação aos judeus ("essa gente vinda não se sabe de onde") em sua forma mais clara: "- O sr. Nehemias nem parece judeu. Gostou tanto do leitão" (Rawet, 2004b, p. 128). Ou seja, reduz a condição judaica à pertença a um grupo religioso e à observância de costumes estranhos, da mesma forma que a Espanha do século XV e o nazismo a associavam a uma marca racial. Mas, sempre, um corpo estranho. Sempre condenando e excluindo o particularismo, com sua conotação negativa, ocultando-se atrás de um: "nem parece...". O equivalente de "negro com alma branca"

No amplo espectro da discriminação, aplicada contra grupos minoritários em geral, deve-se, ainda, incluir a instrumentalização desses grupos com o objetivo de legitimar regimes não tão legítimos, sua utilização como bodes expiatórios. No caso específico dos judeus no Brasil, lembremos do famigerado Plano Cohen, que, a exemplo do que o regime tsarista russo fez com os Protocolos dos Sábios de Sião, foi forjado pelo regime Vargas no final de 1937, associando o "judaísmo internacional" ao "perigo comunista", para aplainar o caminho para a criação do Estado Novo. ${ }^{14}$

\footnotetext{
${ }^{13}$ A esse respeito, ver, entre outros, Flávio Mendes Carvalho (1992),Maria Luiza Tucci Carneiro (1988), Elias Lipiner (1969) e Nelson de Araújo (1991).

${ }^{14}$ Ver, entre outros, Lesser (1995, p. 176 ss.), em especial: "O antissemitismo latente foi uma das justificativas para a mudança em direção ao autoritarismo. No final de setembro de 1937, foi
} 
Após escutar o que cada um dos familiares de seu amigo tem a dizer sobre os judeus, Nehemias se dirige em pensamento ao próprio Jesus, representado em um crucifixo barroco na parede à sua frente, às costas de Nani. Nehemias se identifica com o crucificado, judeu como ele, aproximando o evento de uma reencenação da Última Ceia.

Tu e eu vivemos a perpétua morte e ressurreição pelos séculos afora. Quando teus servos mais dedicados, e dedicados ainda mais a outras inspirações, se aprimoram no zelo: morremos. Quando outros mais brandos, cuja ternura não se desvia da hiena ou do celerado, acolhem-nos com benevolência: vivemos marginais, odiados e temidos (Rawet, 2004b, p. 129).

Num procedimento de personalização que só a literatura possibilita, Rawet coloca as diversas opiniões sobre o judeu, o estrangeiro por excelência - opiniões que variam desde o que poderia ser entendido como filossemitismo até um franco antissemitismo -, na boca de membros de uma mesma família, que assim se torna representativa da sociedade mais ampla. Os membros dessa família literária - bem como a sociedade que eles representam - podem amplamente odiar e discriminar o judeu (ou as minorias que ele representa), mas já não podem ignorá-lo. Sua presença se impõe, e o grupo é forçado a reconhecê-lo, mesmo que seja para expressar seus preconceitos.

Em narrativa densa e concentrada, Rawet oferece ao leitor um amplo espectro do fenômeno do estranhamento, da diferença que separa os grupos humanos, em particular o nacional e os grupos de imigrantes.

Em síntese, o judeu Nehemias Goldenberg, convidado para uma ceia de Natal, percebe o mal disfarçado ódio que aquela família cristã nutre pelos judeus, sobre os quais projetam tudo o que de moralmente condenável encontram em si mesmos: um "senso político extraordinário", graças ao qual "[t]êm o mundo nas mãos"; "grandes financistas, empreendedores",

\footnotetext{
'descoberto' o 'Plano Cohen', uma farsa integralista que afirmava a existência de planos para uma violenta derrubada comunista do governo, que incluía de forma específica o incêndio de igrejas. $\mathrm{O}$ plano, que foi amplamente aceito pela imprensa como legítimo, havia sido concebido por Olympio Mourão Filho, um capitão das forças armadas brasileiras e chefe da seção de propaganda da AIB [Ação Integralista Brasileira], e então repassado para o General Góis Monteiro" (p. 176). Em 1964, já no posto de general de exército, Olympio Mourão Filho participou ativamente do golpe de Estado que implantou a ditadura militar, ao ordenar que suas tropas, em Juiz de Fora, marchassem em direção ao Rio de Janeiro. Ver também Wiazovski (2001, p. 14-15): "O tema do suposto complô judaico mundial ocupou um lugar central no pensamento demonológico de Gustavo Barroso, que traduziu para o português [em 1936] e defendeu as argumentações dos Protocolos dos Sábios de Sião."
} 
eufemismo para "trapaceiros"; "argúcia", que capacita para "uma eterna subversão de fatos, ideias, conceitos, provas, a que consegue sob o impacto de uma oratória bem planejada ofuscar a verdade de um deslize, [...] à que te traz lágrimas aos olhos, em abundância proporcional à renda ou ao renome" (Rawet, 2004b, p. 126). Mas que não esquecem a antiga acusação, rejeitada até pela própria Igreja, ${ }^{15}$ de deicídio.

Nehemias reflete sobre a ideia do Cristo, tão hipocritamente esvaziada pelos cristãos, ao mesmo tempo em que reivindicam sua herança para negar o judaísmo, do qual, para o protagonista, aquela ideia se nutre. Nessa reflexão, nosso herói é levado a uma identificação com o Cristo, à constatação de que ele, Nehemias, na verdade, é o único legítimo seguidor do crucificado naquela família de seguidores que se reuniu para comemorar seu nascimento. A forma de monólogo interior (ou de "diálogo" com quem certamente não responderá) reforça a postura de Nehemias de se manter em silêncio, de se recusar ao papel de vítima propiciatória:

De ti viria a resposta? Humano ou divino, morres constantemente pela nossa vida, e nós morremos sempre a tua morte. Teu apóstolo maior vislumbrou a simbiose eterna, quando, querendo justificarnos e salvar-nos, talvez, plantou a semente de nossa abjeção na nossa simples presença como testemunhas e penhores da remissão global. [...] E que culpa temos se, quando te procuram na feição mais primitiva, no hábito mais original, nos encontram sempre? Se o lamento de Jeremias antecedeu o Sermão da Montanha, se o libelo de Amós precedeu a resposta sobre os direitos de César? E veio o hábito depois, e mesmo aqueles que já não se lembram dessa agonia, e nos vendo, lembram-se que por ela muitas vezes morremos: e nos matam. E desse equívoco gerado em mil anos quando sairemos, tu e eu? (Rawet, 2004b, p. 129).

A possibilidade de olhar para si mesmo através da mediação do Outro - que, então, funciona como um espelho - dá acesso a uma compreensão do Mesmo que a simples auto-observação não permite. Utilizando o que membros de uma família cristã, em meio a uma das principais celebrações cristãs, verbalizam a respeito de judeus na presença de um judeu, e das

\footnotetext{
${ }^{15}$ Ver a declaração "Nostra aetate”, aprovada em 1965 no Concílio Vaticano II: "Ainda que as autoridades dos judeus e seus seguidores tenham reclamado a morte de Cristo, o que em sua Paixão se fez não pode ser imputado nem indistintamente a todos os judeus que então viviam, nem aos judeus de hoje".
} 
reflexões que essas falas cristãs provocam no judeu, que as escuta sem reagir, Rawet aborda as formas com que os grupos em oposição representam um ao outro, e como se veem representados pelo outro. A mediação dessa família "nacional" permite que Nehemias atinja um novo patamar de compreensão de sua identidade judaica.

\section{Referências}

ALMEIDA, Guilherme de (1962). Cosmópolis. São Paulo: Companhia Editora Nacional.

ARAÚJO, Nélson de (1991) 1591: a Santa Inquisição na Bahia e outras estórias. Rio de Janeiro: Nova Fronteira.

BHABHA, Homi K. (1998). O local da cultura. Tradução de Myriam Ávila, Eliana Lourenço de Lima Reis e Gláucia Renate Gonçalves. Belo Horizonte: Editora da UFMG.

CAMPOS, Humberto de (1933). Em favor de Israel. In: LIMA, Marcio Campos (Org.). Os judeus na Allemanha no momento actual. Rio de Janeiro: Flores \& Mano, p. 13-19.

CAMPOS, Humberto de (1954). Em favor de Israel. In: CAMPOS, Humberto de. Os Párias. Rio de Janeiro; São Paulo; Porto Alegre: W. M. Jackson, p. 245-251.

CARNEIRO, Maria Luiza Tucci (1988). Preconceito racial: Portugal e BrasilColônia. 2. ed. São Paulo: Brasiliense.

CARVALHO, Flávio Mendes (1992). Raízes judaicas no Brasil: o arquivo secreto da Inquisição. São Paulo: Nova Arcádia.

COSTA, Flávio Moreira da (1972). Rawet fala de Rawet. Correio da Manhã, Rio de Janeiro, 18 jun.

ETTINGER, S. (1976). The Modern period. In: BEN-SASSON, Haim Hillel (Ed.). A history of the Jewish people. Cambridge: Harvard University Press, p. 725-1.096.

KRISTEVA, Julia (1994). Estrangeiros para nós mesmos. Tradução de Maria Carlota Carvalho Gomes. Rio de Janeiro: Rocco.

LESSER, Jeffrey (1995). O Brasil e a questão judaica: imigração, diplomacia e preconceito. Tradução de Marisa Sanematsu. Rio de Janeiro: Imago.

LESSER, Jeffrey (2001). A negociação da identidade nacional: imigrantes, minorias e a luta pela etnicidade no Brasil. Tradução de Patrícia de Queiroz Carvalho Zimbres. São Paulo: Editora da Unesp. 
LIPINER, Elias (1969). Os judaizantes nas Capitanias de Cima: estudos sobre os cristãos-novos do Brasil nos séculos XVI e XVII. São Paulo: Brasiliense.

MOOG, Vianna (1966). Um rio imita o Reno. 8. ed. Rio de Janeiro: Civilização Brasileira.

NEEMIAS (1965). In: A BÍBLIA. Tradução de João Ferreira de Almeida. Rio de Janeiro: Sociedade Bíblica do Brasil.

RAWET, Samuel (2004a). Gringuinho. In: RAWET, Samuel. Contos e novelas reunidos. Rio de Janeiro: Civilização Brasileira, p. 42-45.

RAWET, Samuel (2004b) Natal sem Cristo. In: RAWET, Samuel. Contos e novelas reunidos. Rio de Janeiro: Civilização Brasileira, p. 123-129.

RUSHDIE, Salman (2008). Os versos satânicos. Tradução de Misael Dursan. São Paulo: Companhia das Letras.

SALGADO, Plínio (1948). O Estrangeiro. 5. ed. São Paulo: Companhia Editora Panorama.

VERÍSSIMO, Érico (1955). O tempo e o vento. 6. ed. Rio de Janeiro; Porto Alegre; São Paulo: Globo, 3 v.

WIAZOVSKI, Taciana (2001). Bolchevismo e judaísmo: a comunidade judaica sob o olhar do Deops. São Paulo: Arquivo do Estado; Imprensa Oficial.

Recebido em março de 2016.

Aprovado em julho de 2016.

\section{resumo/abstract/resumen}

\section{A autorrepresentação do judeu mediada pelo olhar do nacional em "Natal sem Cristo" de Samuel Rawet}

Saul Kirschbaum

Rawet nasceu na Polônia em 1929 e imigrou para o Brasil em 1936. Tendo vivido seus primeiros anos em um shtetl, sua infância foi marcada pela onipresença da ambiência judaica. $\mathrm{O}$ afastamento desse meio ambiente, colocando-o em contato com uma população majoritariamente não-judaica, irá desenvolver sua autopercepção de imigrante, um estranhamento que marcará toda sua obra. Por outro lado, Rawet acabou por afastar-se radicalmente da própria comunidade judaica, à qual acusou, em 1977, de mineralidade. Colocado, assim, na situação kafkiana de não ter para onde ir e nem para onde voltar, viu-se em posição 
privilegiada para refletir, em sua ficção, as dificuldades de convívio, que se manifestam, na literatura, como representação: como o judeu representa os nacionais e como se vê representado por eles. Em "Natal sem Cristo" (Diálogo, 1963), Nehemias, judeu, professor de história, 30 anos, é convidado por um amigo cristão para a ceia de Natal com sua família. É a ocasião perfeita para vermos como, na opinião de Rawet, cada membro da família vê aquele ser estranho, e como o protagonista avalia as atitudes de cada um em relação aos judeus.

Palavras-chave: Samuel Rawet, estranhamento, imigrantes, antissemitismo.

\section{Jewish self-representation as mediated by a national look in Samuel Rawet's "Christmas without Christ"}

\section{Saul Kirschbaum}

Rawet was born in Poland in 1929 and immigrated to Brazil in 1936. Having lived his early years in a shtetl, his childhood was marked by the omnipresence of a Jewish ambience. The departure from this environment puts him in touch with a mostly non-Jewish population, and develops his immigrant self-awareness, an estrangement that will mark all his work. Rawet departed radically from the Jewish community itself, which he accused in 1977 of minerality. Placed thus in the Kafkaesque situation of not having where to go nor where to return, he was in a unique position to reflect in his fiction about the difficulties of living, manifested in literature as representation: how the Jew represents national subjects and how he sees himself represented by them. In "Christmas without Christ" (Diálogo, 1963), Nehemias, a 30 year old Jew and a professor of history, is invited by a Christian friend for Christmas dinner with his family. It's the perfect occasion to see how, in Rawet's opinion, each family member sees that strange being - the Jew, and how the protagonist assesses the attitude of each one in relation to the Jews.

Keywords: Samuel Rawet, estrangement, immigrants, anti-Semitism.

\section{La auto-representación del judío mediada por la mirada del nacional en "Navidad sin Cristo" de Samuel Rawet}

\section{Saul Kirschbaum}

Rawet nació en Polonia en 1929 y emigró a Brasil en 1936. Su infancia estuvo marcada por la omnipresencia del ambiente judio, después de haber vivido sus primeros años en un shtetl. La exclusión posterior de este ambiente lo puso en contacto con una población en su mayoría no judía, provocando el desarrollo de una conciencia de sí mismo como inmigrante, un distanciamento que marcará toda su obra. Por otro lado, Rawet vino a apartarse radicalmente de la propia comunidad judía, que acusó en 1977 de "mineralidad". Colocado de este modo 
en la posición kafkiana de no tener a donde ir así como de no tener a dónde volver, él se vio en una posición única para reflejar, en su ficción, las dificultades del convivir, que se manifiestan en la literatura como representación: la forma como el judio representa a los nacionales y como se ve representado por ellos. En "Natal sem Cristo" (Diálogo, 1963), Nehemias, judío, profesor de historia, de 30 años de edad, es invitado por un amigo cristiano para la cena de Navidad con su família. Es la ocasión perfecta para ver cómo, en la opinión de Rawet, cada miembro de la família ve a aquel ser extraño, y cómo el protagonista evalúa las actitudes de cada uno en relación con los judíos.

Palabras clave: Samuel Rawet, distanciamiento, inmigrantes, antisemitismo. 